\title{
Implementasi Access Control List Pada Mikrotik dalam Mengamankan Koneksi Internet Koperasi Sumber Dana Mutiara
}

\author{
Bil Klinton Sihotang, Sumarno, Bahrudi Effendi Damanik
}

\author{
Program Studi Sistem Informasi, STIKOM Tunas Bangsa, Pematangsiantar, Indonesia \\ Email : *,1 bilklintonsihotang@gmail.com \\ Submitted 31-01-2020; Accepted 27-02-2020; Published 26-04-2020
}

\begin{abstract}
Abstrak
Kebutuhan akan informasi dan akses internet pada saat ini sangat tinggi. Untuk memenuhi itu salah satunya dengan jaringan komputer sebagai medianya. Dalam sebuah jaringan terutama jaringan yang sudah disegmentasi menggunakkan Virtual Local Local Area Network (VLAN) dibutuhkan penerapan Access Control List (ACL) untuk mengatur hak akses tiap perangkat yang ada di dalam jaringan tersebut. Access Control List (ACL) dapat menyaring lalu lintas data suatu jaringan dengan mengontrol apakah paket-paket tersebut dilewatkan atau dihentikan. Jaringan dibangun menggunakan dengan beberapa perangkat jaringan yang berbeda - beda, salah satunya adalah router. Router merupakan alat yang dapat memproses paket data berbeda jaringan (antar jaringan) melalui proses yang disebut dengan routing. banyak sekali perusahaan yang memproduksi router, mikrotik adalah salah satu perusahaan yang memproduksi router. mikrotik mudah dioperasikan karena menggunakan winbox dalam tampilan Gui, Selain itu terdapat hotspot server yang didalamnya terdapat beberapa fasilitas menegement yang dapat diatur sesuai dengan kebutuhan jaringan.
\end{abstract}

Kata Kunci: Kata Kunci : Jaringan Komputer, Access Control List, Mikrotik, Router, Winbox

Abstract

The need for information and internet access at this time is very high. To accept it is wrong only with computer networks as a medium. In a network that requires a network that has been segmented using a Virtual Local Area Network (VLAN), the application of an Access Control List (ACL) is required to be granted access rights for each device in the network. The Access Control List (ACL) can filter the data traffic of a network by controlling whether the packets are passed or issued. A network is built using several different network devices, one of which is a router. A router is a tool that can process different data packet networks (between networks) through a process called routing. lots of companies that produce routers, mikrotik is one of the companies that produce routers. mikrotik is easy to do because it uses Winbox in Gui's view, besides that the hotspot server in it is provided with several management facilities that can be arranged according to network requirements.

Keywords: Computer Network, Access Control List, Microtik, Router, Winbox

\section{PENDAHULUAN}

Jaringan komputer saat ini merupakan suatu layanan yang sangat dibutuhkan. Jaringan komputer mempunyai manfaat yang lebih dibandingkan dengan komputer yang berdiri sendiri. Jaringan komputer memungkinkan pemakaian secara bersama baik data, perangkat lunak dan peralatan. Sehingga kelompok kerja dapat berkomunikasi lebih efektif dan efisien.

Saat ini jaringan internet sangat meningkat kegunaannya di kalangan masyarakat. Mulai dari kalangan sekolah, kantor, perusahaan maupun di kalangan masyarakat biasa sudah menggunakan sistem jaringan komputer. Tujuannya agar pengguna dapat saling berkomunikasi antara satu dengan yang lainnya. Hal ini memicu orang-orang yang kurang bertanggung jawab untuk melakukan hal-hal yang dapat mengganggu sistem keamanan komunikasi data dalam sebuah jaringan. Misalnya saja mencuri informasi, atau sekedar iseng ingin belajar memanipulasi sebuah jaringan. Hal tersebut membuat kita harus berhati-hati dalam menentukan sistem keamanan komunikasi data dalam sebuah jaringan.

Sistem keamanan jaringan menjadi faktor yang sangat penting untuk dipertimbangkan bagi seorang administrator jaringan, Kelemahan jaringan wireless secara umum dapat dibagi menjadi 2 jenis, yakni kelemahan pada konfigurasi dan kelemahan pada jenis enkripsi yang digunakan. Salah satu contoh penyebab kelemahan pada konfigurasi karena saat ini untuk membangun sebuah jaringan wireless cukup mudah. Banyak vendor yang menyediakan fasilitas yang memudahkan pengguna atau admin jaringan sehingga sering ditemukan wireless yang masih menggunakan konfigurasi wireless default bawaan vendor. Tidak jarang ditemukan jaringan wireless yang dipasang masih menggunakan setting default bawaan vendor seperti SSID, IP Address, remote manajemen, DHCP enable, kanal frekuensi, tanpa enkripsi bahkan user/password untuk administrasi wireless tersebut[1].

Access Control List (ACL) adalah salah satu alternatif upaya untuk mengamankan jaringan komputer. Access control list merupakan pengelompokan paket berdasarkan kategori. $A C L$ bisa sangat membantu ketika membutuhkan pengontrolan dalam lalu lintas network. Access Control List menjadi tool pilihan untuk pengambilan keputusan pada situasi ini. Access Control List (ACL) sederhananya digunakan untuk mengijinkan atau tidak paket dari host menuju ke tujuan tertentu. Access Control List (ACL) terdiri atas aturan-aturan dan kondisi yang menentukan trafik jaringan dan menentukan proses di router apakah nantinya paket akan dilewatkan atau tidak. Penggunaan access Control list (ACL) yang paling umum dan paling mudah untuk dimengerti adalah penyaringan paket yang tidak diinginkan ketika mengimplementasikan kebijakan keamanan[2]. Untuk mengoptimalkan proses implementasi $A C L$ pada koperasi Sumber Dana Mutiara, maka penulis menggunakan perangkat tambahan yang berfungsi sebagai router yaitu mikrotik. Mikrotik pada dasarnya dikenal dengan kestabilan, kualitas kontrol dan fleksibilitas untuk berbagai jenis paket data dan penanganan proses rute atau lebih dikenal dengan istilah routing. Mikrotik yang dibuat sebagai router banyak bermanfaat untuk sebuah ISP yang ingin menjalankan beberapa aplikasi mulai dari hal yang paling ringan hingga tingkat lanjut. 


\section{METODE PENELITIAN}

\subsection{Access Control List}

Access Control adalah mekanisme untuk mengatur "siapa yang boleh melakukan apa " dan "dari mana dan boleh ke mana". Penerapannya membutuhkan klasifikasi data (public, private,confident, secret) dan berbasiskan role (kelompok atau grup hak akses)[3]. Menururut penulis ACL (Access Control List) merupakan metode selektivitas terhadap packet data yang akan dikirimkan pada alamat yang dituju. Secara sederhana $A C L$ dapat kita ilustrasikan seperti sebuah standard keamanan. Hanya paket yang memiliki kriteria yang sesuai dengan aturan yang diperbolehkan melewati gerbang keamanan, dan bagi paket yang tidak memiliki kriteria yang sesuai dengan aturan yang diterapkan, maka paket tersebut akan ditolak. ACL dapat berisi daftar IP address, MAC Address, subnet, atau port yang diperbolehkan maupun ditolak untuk melewati jaringan.

Jenis - Jenis Access Control list

1. Standard ACL

Standard ACL merupakan jenis ACL yang paling sederhana. ACL ini diterapkan pada router tujuan. mengizinkan atau menolak paket hanya berdasarkan alamat sumber[4]. Alamat sumber yang dimaksud dapat berupa alamat sumber dari jaringan (Network Address) atau alamat sumber dari host. Standard ACL dapat diimplementasikan pada proses filtering protocol TCP, UDP atau pada nomor port yang digunakan. Meskipun demikian, Standard ACL hanya mampu mengijinkan atau menolak paket berdasarkan alamat sumbernya saja.

2. Extended ACL

Extended ACL merupakan jenis $A C L$ yang mampu memberikan tingkat keamanan yang lebih baik ketimbang Standard $A C L$. ACL ini diterapkan pada router sumber. mengizinkan atau menolak paket berdasarkan sumber dan juga alamat tujuan[4]. Selain itu Extended ACL memberikan keleluasaan kepada admin jaringan dalam melakukan proses filtering dengan tujuan yang lebih spesifik.

\subsection{Mikrotik}

Menurut [5] Mikrotik adalah sebuah merek dari sebuah perangkat jaringan, pada awalnya mikrotik hanyalah sebuah perangkat lunak atau software yang di-install komputer yang digunakan untuk mengontrol jaringan, tetapi dalam perkembangannya saat ini telah menjadi sebuah device atau perangkat jaringan yang handal dan harga yang terjangkau, serta banyak digunakan pada level perusahan penyedia jasa internet (ISP).

Mikrotik adalah sebuah perusahaan kecil berkantor pusat di Latvia, bersebelahan dengan Rusia. Pembentukannya diprakarsai oleh John Trully dan Arnis Riekstins. John Trully adalah seorang berkewarganegaraan Amerika yang berimigrasi ke Latvia. Di Latvia ia bejumpa dengan Arnis, Seorang darjana Fisika dan Mekanik sekitar tahun 1995. John dan Arnis mulai me-routing dunia pada tahun 1996 (misi Mikrotik adalah me- routing seluruh dunia). Mulai dengan sistem Linux dan MS-DOS yang dikombinasikan dengan teknologi Wireless-LAN (WLAN) Aeronet berkecepatan 2 Mbps di Moldova, negara tetangga Latvia, baru kemudian melayani lima pelanggannya di Latvia.

\subsection{Internet}

Menurut [6] Internet of Things (IoT) merupakan suatu jaringan yang menghubungkan berbagai objek yang memiliki identitas pengenal serta alamat IP, sehingga dapat saling berkomunkasi dan bertukar informasi mengenai dirinya maupun lingkungan yang di daeranya. Objek-objek dalam IoT dapat menggunakan maupun menghasilkan layanan-layanan dan saling bekerjasama untuk mencapai suatu tujuan bersama.

Penggunanya dapat mencakup semua usia, dari kalangan kanak-kanak sampai dewasa. Begitu pula dengan dunia pendidikan, internet telah menjadi salah satu fasilitator utama dalam pelaksanaan proses belajar mengajar pada institusiinstitusi pendidikan di seluruh penjuru dunia. Digitalisasi bahkan telah diimplementasikan pada institusi pendidikan di negara -negara berkembang di seluruh dunia, seperti pengajaran menggunakan presentasi digital, pengumpulan tugas secara online dan lain sebagainya.

\section{HASIL DAN PEMBAHASAN}

Spesifikasi sistem yang digunakan dalam implementasi jaringan berbasis router mikrotik pada Koperasi Sumber Dana Mutiara menggunakan hardware dan software yang seperti yang disebutkan pada poin - poin di bawah ini. Dibawah ini adalah spesifikasi Perangkat Keras yang akan digunakan dalam implementasi jaringan berbasis router mikrotik pada Koperasi Sumber Dana Mutiara.

Router yang akan di digunakan di Koperasi Sumber Dana Mutiara adalah keluaran dari mikrotik dengan tipe mikrotik RB91UI-2ND spesifikasi lengkap Router tersebut dapat dilihat pada tabel di bawah ini.

Tabel 1. Spesifikasi Mikrotik RB951Ui-2nD

\begin{tabular}{cc}
\hline Product Code & RB951Ui-2 \\
\hline Architecture & MIPS-BE \\
CPU & QCA9531-BL3A-R 650MHz \\
Main Storage/NAND & $16 \mathrm{MB}$
\end{tabular}




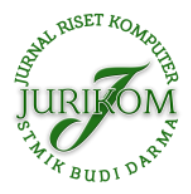

\begin{tabular}{cc}
\hline RAM & $64 \mathrm{MB}$ \\
LAN Ports & 5 \\
Gigabit & No \\
Switch Chip & 1 \\
Integrated Wireless & 1 \\
Wireless Standarts & $802.11 \mathrm{~b} / \mathrm{g} / \mathrm{n}$ \\
Wireless Tx Power & $22 \mathrm{dbm}$ \\
Integrated Antenna & Yes \\
Antenna Gain & $2 \times 1,5 \mathrm{dBi}$ \\
USB & 1 \\
Power on USB & Yes \\
Power Jack & $8-30 \mathrm{~V}$ \\
POE Input & Yes \\
POE Output & Yes, Port 5 \\
Dimentions & $113 \mathrm{x} 89 \mathrm{x} 28 \mathrm{~mm}$. \\
Operating System & RouterOS \\
Temperature Range & $-20 \mathrm{C} . .+50 \mathrm{C}$ \\
RouterOS License & Level4 \\
\hline
\end{tabular}

Dalam melakukan implementasi dan evaluasi jaringan berbasis router mikrotik pada Koperasi Sumber Dana Mutiara digunakan software Winbox. Aplikasi Winbox yang digunakan untuk melakukan konfigurasi pada router adalah Winbox versi 5.13, Dengan Winbox lebih mudah untuk melakukan konfigurasi dari pada menggunakan CLI (Command Line Interface).

\subsection{Konfigurasi Access Control List}

Apabila semua kebutuhan yang mendukung perancangan Access Control List sudah terpenuhi, maka langkah yang harus dilakukan adalah menginstal Winbox, untuk mengkonfigurasi routerboard mikrotik, Winbox dapat di download pada browser.

Di aplikasi winbox kita dapat mengkonfigurasi mikrotik sebelum melakukan konfigurasi access control list terlebih dahulu admin harus melakukan konfigurasi awal seperti konfigurasi IP, Hotspot, dan DNS.

Setelah selesai melakukan konfigurasi pada wlanl langkah selanjutnya adalah mengatur wireless agar dapat melakukan Access Control List. Cara yang digunakan adalah melakukan konfigurasi pada wlanl -> hapus centang pada Default Authenticate dapat dilihat pada gambar 1.

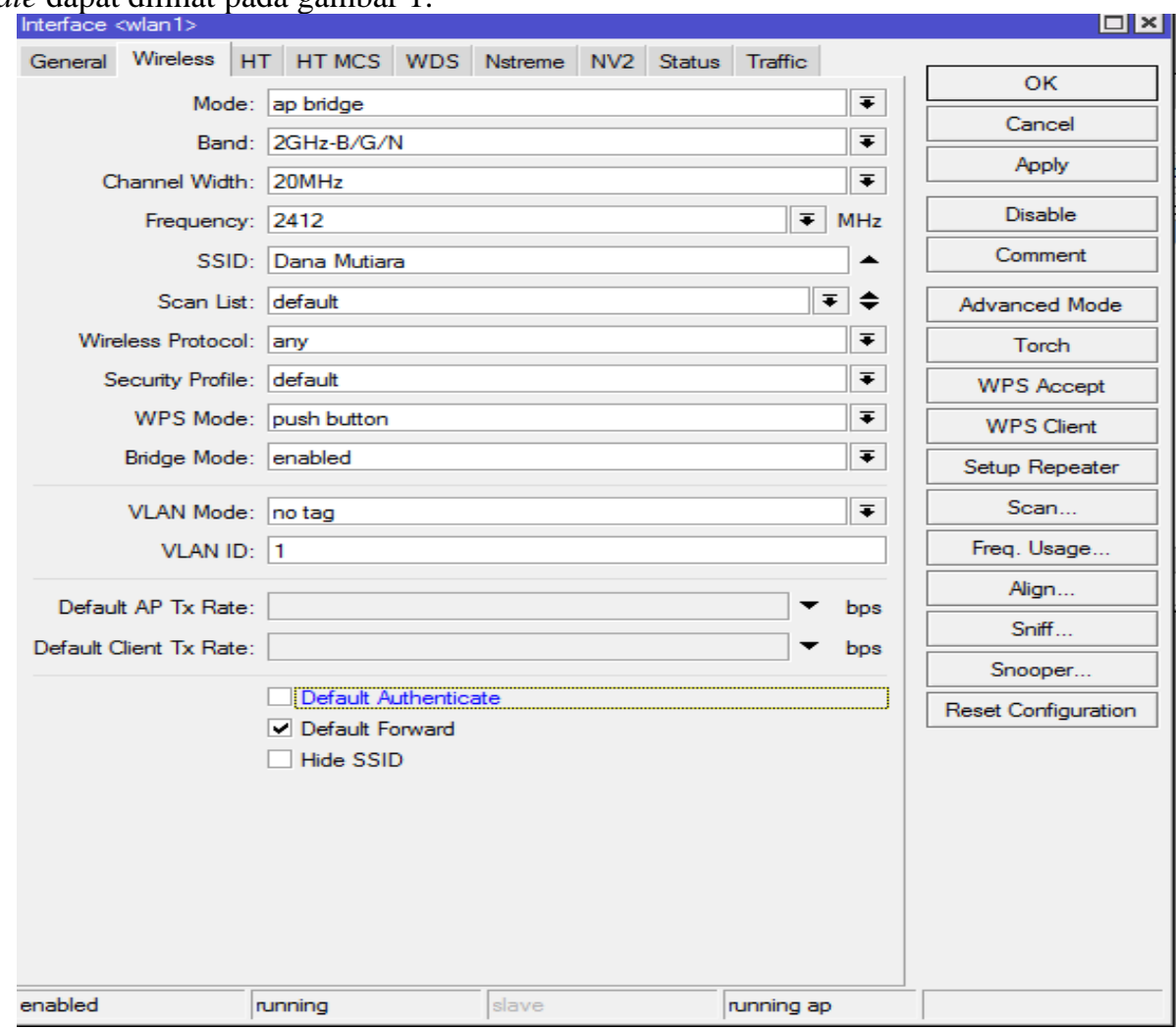

Gambar 1. Hapus Default Authenticate 


\subsection{Pengujian Access Control List}

Tahap pengujian ini dimaksudkan untuk melihat apakah Access Control List berhasil diimplementasikan di jaringan Dana Mutiara dengan baik, dengan melakukan pengujian melalui user client, ketika client yang digunakan dihubungkan ke Wifi Dana Mutiara maka user tersebut tidak dapat terhubung sama sekali ke jaringan Wifi seperti gambar 2.

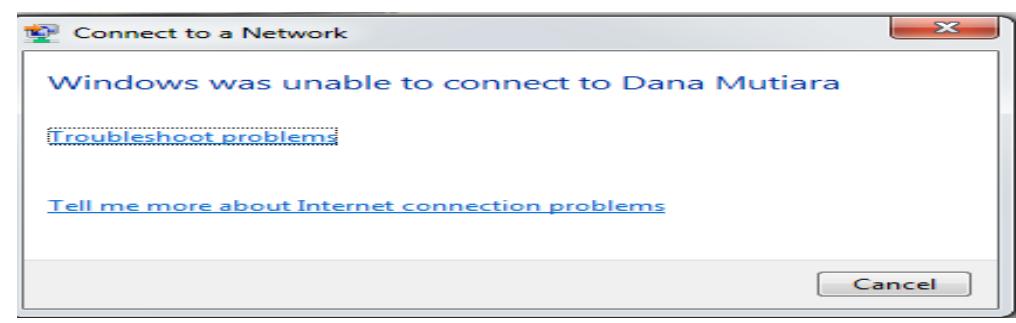

Gambar 2. User Tidak Dapat Terhubung

Agar dapat masuk ke jaringan Wifi Dana Mutiara, user harus mengetahui Mac Address Wireless Lan Adapter dari perangkat yang digunakan, yang dapat di cek melalui $C M D$ seperti gambar 3 .

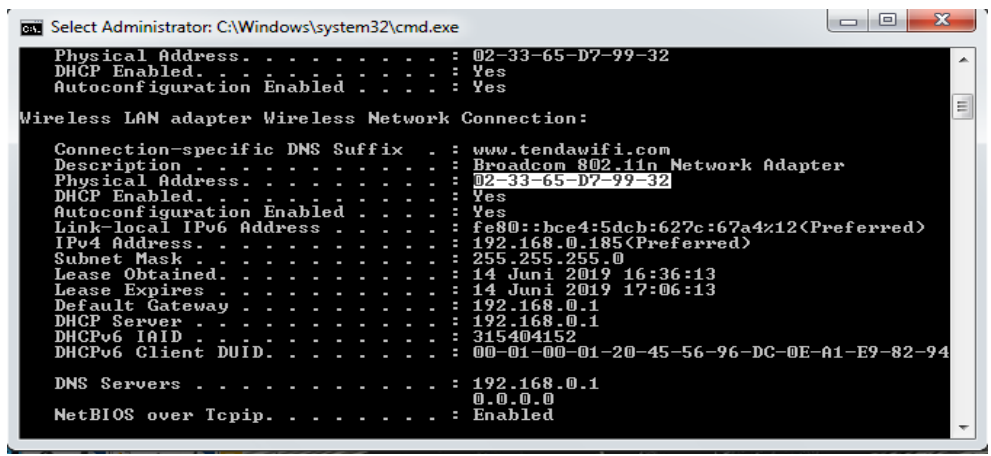

Gambar 3. Mac Address User

Untuk dapat masuk ke jaringan Dana Mutiara maka Mac Address user harus didaftarkan ke dalam Access List seperti gambar 4.

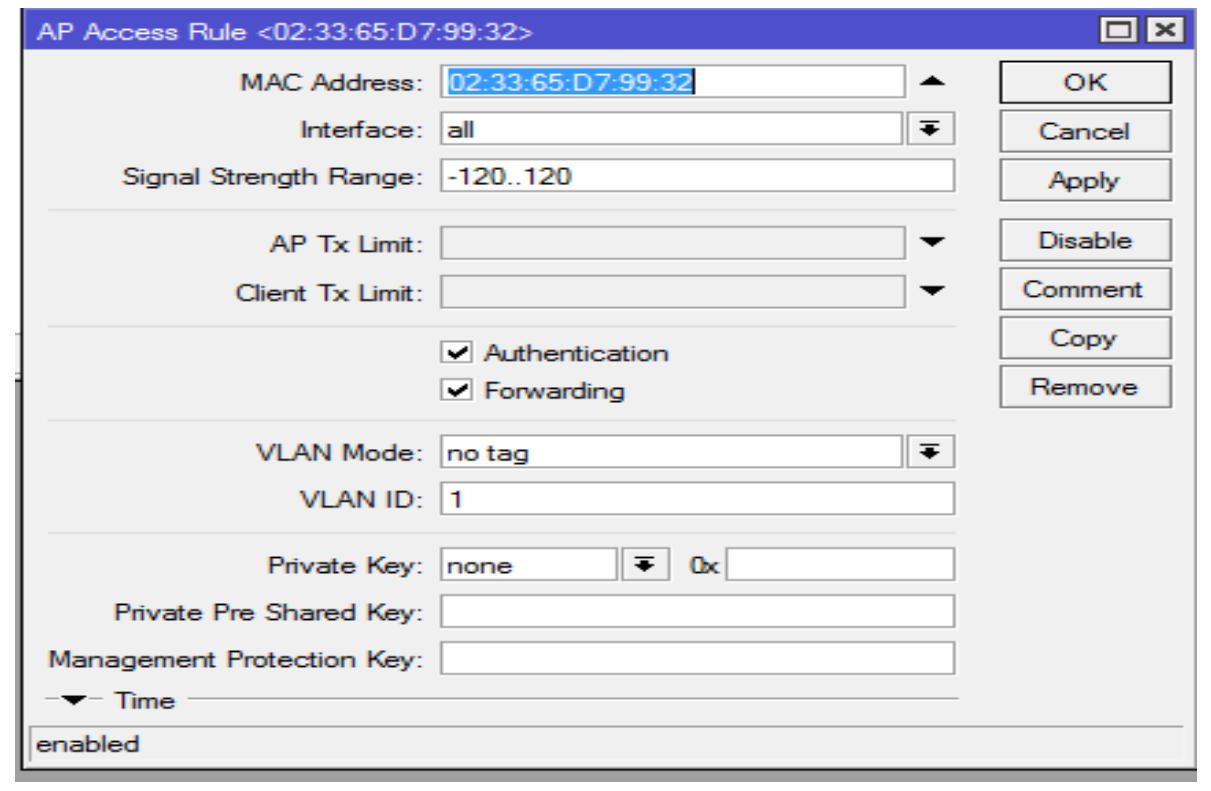

Gambar 4. Menambahkan User ke Acess List

Setelah Mac Address didaftarkan ke Access List maka user sudah dapat terhubung ke jaringan Wifi Dana Mutiara tetapi belum dapat mengakses internet seperti gambar 5 . 


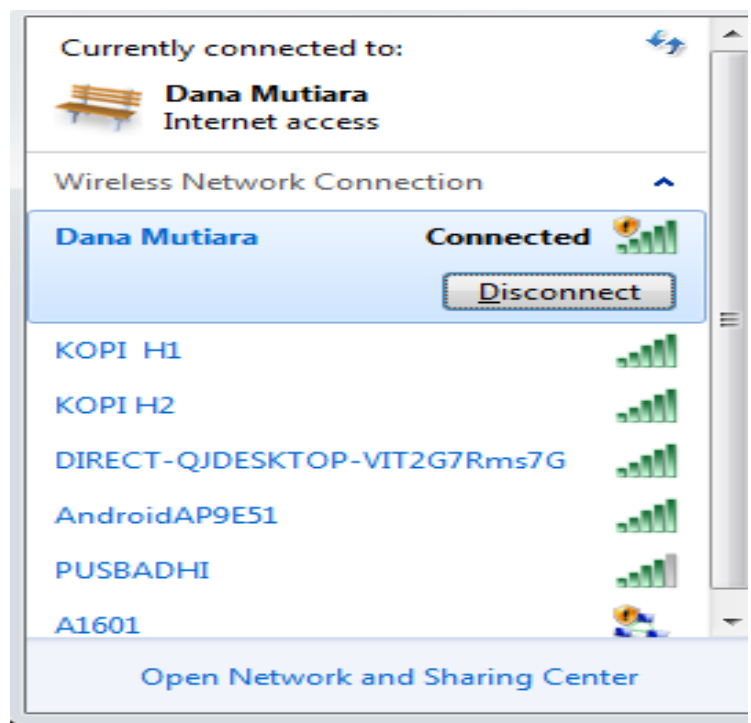

Gambar 5. User Dapat Terhubung

Agar user dapat terhubung ke internet, maka user harus login terlebih dahulu melalui browser dengan masuk ke domain www.danamutiara.com, dan memasukkan id dan password yang telah telah terdaftar saat konfigurasi hotspot di mikrotik dengan id : admin dan password : 123456 seperti gambar 6.

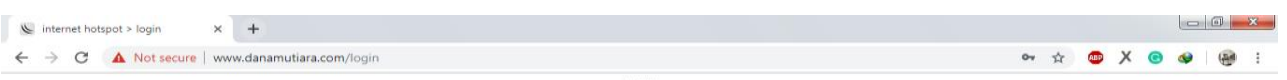

Gambar 6. Tampilan Login Mikrotik

Jika id dan password yang dimasukkan benar maka akan mucul tampilan status user yang menandakan bahwa user sudah berhasil login ke jaringan seperti gambar 7.
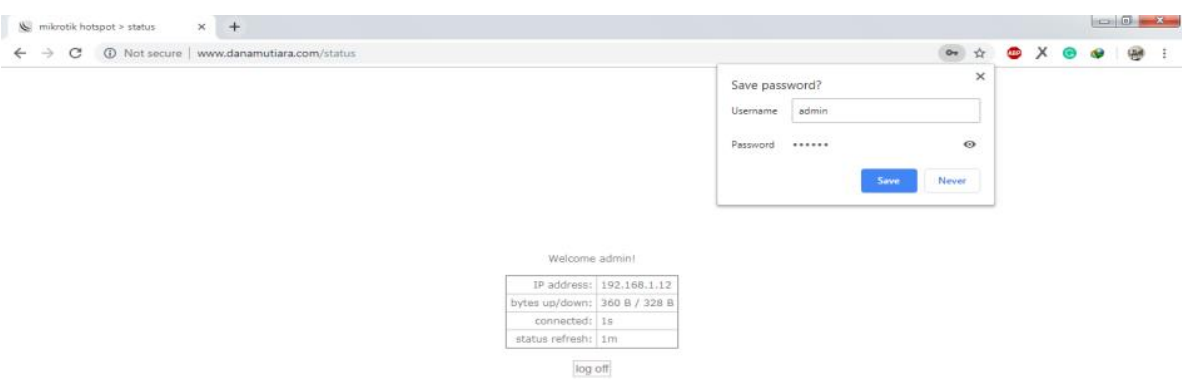

Gambar 7. Tampilan Setelah Berhasil Login 


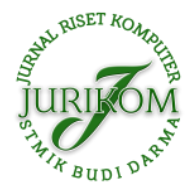

JURIKOM (Jurnal Riset Komputer), Vol. 7 No. 2, April 2020 e-ISSN 2715-7393 (Media Online), p-ISSN 2407-389X (Media Cetak) DOI 10.30865/jurikom.v7i2.2010 Hal 229-234

Untuk melakukan pengujian bahwa PC user telah terhubung ke internet maka di lakukan ping test google melalui CMD seperti gambar 8 .

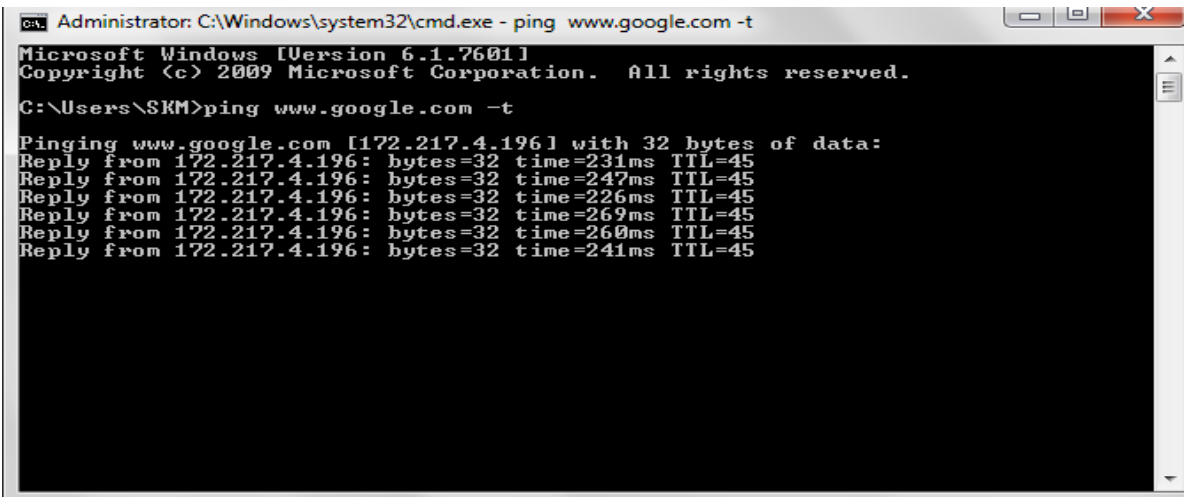

Gambar 8. Ping Test Google.com

\section{KESIMPULAN}

Setelah melaksanakan penelitian dan pengujian terhadap ACL (Access Control List) dengan menggunakan router Mikrotik RB91UI-2ND pada hotspot Dana Mutiara, maka dapat diambil kesimpulan sebagai berikut:

a. Dengan memanajemen user ACL (Access Control List) dengan mikrotik RB91UI-2ND pada login hotspot di Koperasi Sumber Dana Mutiara hanya Mac Address yang terdaftar saja yang dapat mengakses hotspot sehingga jaringan hotspot lebih private.

b. Biaya membangun jaringan mikrotik dengan menggunakan mikrotik routerboard mempunyai harga yang relatif lebih murah dibandingkan menggunakan $P C$ sebagai mikrotik router.

c. Dari sisi administrator, sistem ACL pada mikrotik hotspot dapat lebih mempermudah dalam hal pemeliharaan dan monitoring. Karena admin dapat memilih siapa - siapa saja yang dapat mengakses hotspot melalui Mikrotik RB91UI$2 N D$.

\section{REFERENCES}

[1] I. K. Bayu, M. Yamin, and L. F. Aksara, "Analisa Keamanan Jaringan Wlan Dengan Metode Penetration Testing (Studi Kasus: Laboratorium Sistem Informasi dan Programming Teknik Informatika UHO,”SemanTIK, vol. 3, no. 2, pp. 69-78, 2017.

[2] P. Simanjuntak et al., "Analisis Penggunaan Access Control List ( Acl ) Dalam Jaringan Komputer Di Kawasan,” J. Teknol. Inf. Politek. Telkom, vol. 1, no. 1, pp. 1-35, 2019, doi: .1037//0033-2909.I26.1.78.

[3] Herawati and N. Mintarsih, "PENINGKATAN KEAMANAN APLIKASI KONTROL DENGAN MENGGUNAKAN METODE FIREWALLDAN KASPERSKY ENDPOINT SECURITY 8 ABSTRAK," vol. 7, no. 11, pp. 30-33, 2014.

[4] S. Suman and A. Agrawal, "IP Traffic Management With Access Control List Using Cisco Packet Tracer," Int. J. Sci. Eng. Technol. Res., vol. 5, no. 5, pp. 2278-7798, 2016.

[5] A. Malik, L. F. Aksara, and M. Yamin, "Perbandingan Metode Simple Queues Dan Queues Tree Untuk Optimasi Manajemen Bandwidth Menggunakan Mikrotik (Studi Kasus: Pengadilan Tinggi Agama Kendari)," semanTIK, vol. 3, no. 2, pp. 1-8, 2017.

[6] E. D. Meutia, "Internet of Things - Keamanan dan Privasi," Semin. Nas. dan Expo Tek. Elektro 2015, pp. 85-89, 2015. 